\title{
Spatial Analysis of Sleeping Sickness, Southeastern Uganda, 1970-2003
}

\author{
Lea Berrang-Ford, ${ }^{*}$ Olaf Berke, ${ }^{*} \dagger$ Lubowa Abdelrahman,‡ David Waltner-Toews, ${ }^{*}$ \\ and John McDermott*§
}

Sleeping sickness reemerged in southeastern Uganda in the 1970s and remains a public health problem. It has continued to spread north into new districts, and gaps remain in the understanding of the causes of its spread and distribution. We report the distribution and magnitude of sleeping sickness in southeastern Uganda from 1970 to 2003. Data were collected from records of the Ugandan Ministry of Health, individual sleeping sickness treatment centers, and interviews with public health officials. Data were used to develop incidence maps over time, conduct space-time cluster detection analyses, and develop a velocity vector map to visualize spread of sleeping sickness over time in southeastern Uganda. Results show rapid propagation of sleeping sickness from its epicenter in southern Iganga District and its spread north into new districts and foci.

leeping sickness is the human form of African try$\checkmark$ panosomiasis (caused by Trypanosoma spp.), a protozoal parasitic disease affecting humans, livestock, and many sylvatic species in sub-Saharan Africa. It is transmitted by the tsetse fly vector (Glossina spp.) and in cattle is a serious constraint to livestock development in subSaharan Africa (1-3).

The acute form of sleeping sickness, which is caused by Trypanosoma brucei rhodesiense and is predominant in eastern and southern Africa (4-6), is present in southeastern Uganda (Figure 1). Sleeping sickness is a serious public health problem in this region; epidemics have occurred in 1901-1915, 1940-1946, and 1976-1989 (3). More recently, spread of sleeping sickness into areas previously

*University of Guelph, Guelph, Ontario, Canada; †University of Veterinary Medicine, Hannover, Germany; łMakerere University, Kampala, Uganda; and SInternational Livestock Research Institute, Nairobi, Kenya thought to be free from the disease has highlighted gaps in the ability of current research to explain and predict the distribution of infection (7).

In 1976, an outbreak was detected in Luuka County in western Iganga District, outside the traditional fly zone. This was the beginning of an extensive epidemic that eventually spread throughout southeastern Uganda. This outbreak occurred during a time of great political instability and civil conflict in Uganda, which contributed to a reduction of resources and services for sleeping sickness (8). Although the incidence of sleeping sickness decreased in southeastern Uganda in the early 1990s, it continues to persist and spread in 2005. An outbreak was detected for the first time in Soroti District in 1998 (7), followed by

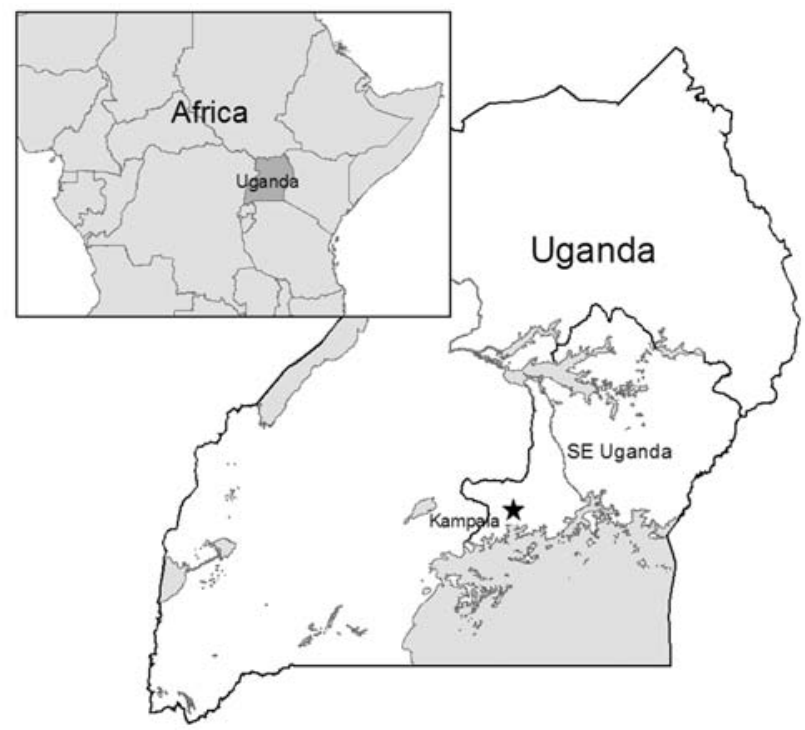

Figure 1. Location of the study site in southeastern (SE) Uganda. The star indicates the capital of Kampala. Inset shows surrounding countries in Africa. 
continued spread north into Kumi, Kaberamaido, and Lira Districts $(9,10)$. Historical analyses of sleeping sickness in southeastern Uganda can improve disease control by increasing understanding of the context and trends of the disease, as well as identifying variables associated with these trends. Additionally, historical analyses may validate hypothesized processes.

We describe and characterize the spatial distribution of $T$. b. rhodesiense sleeping sickness in southeastern Uganda for a 34-year epidemic period (1970-2003). We hypothesize that sleeping sickness in southeastern Uganda is driven by 2 dominant processes. In process $\mathrm{A}$, in regions where disease occurs or has recently occurred, localized outbreaks are triggered by processes that increase tsetse populations or by changes that increase human-tsetse contact. In process $\mathrm{B}$, in regions where disease has not recently occurred, spread is facilitated by movement of infected livestock into uninfected regions.

\section{Methods}

\section{Study Area}

The study area in southeast Uganda in eastern Africa (Figure 1) is subdivided into 17 districts, 46 counties, and 254 subcounties. The region has an area of $\approx 55,000 \mathrm{~km}^{2}$ and a population of $\approx 9$ million (11). Thirteen percent live in the capital of Kampala (11), and the remainder live in predominantly rural areas dominated by livestock and subsistence farming $(12,13)$.

\section{Data Collection}

Cross-sectional sleeping sickness data from 1970 to 2003 were collected retrospectively in 2004 to identify case counts and measures of disease magnitude per subcounty per year. Data were collected for all available records of sleeping sickness patients in southeastern Uganda. Data availability and reliability varied between years on the basis of quality of surveillance and primary data collection, as well as availability of records and recall bias for secondary data collection. Reliability of data for 1986 to 2003 was considered moderate to high, but reliability of data for 1970 to 1986 was low to moderate. Evaluation and review of data by public health officials concluded that information on disease prevalence and absence was reliable for most years, but measures of disease magnitude were less reliable before 1986 .

Since 1999, sleeping sickness data summaries have been provided by the National Sleeping Sickness Control Program at the Ugandan Ministry of Health. For data before 1988, no centralized collection of records exists beyond district summaries; sleeping sickness case data remain in records at individual treatment centers. Data before 1988 were collected retrospectively in 2004 during visits to all treatment centers active in the 1980s. In many cases, record books were poorly stored, damaged, had lost pages, or were missing (Figure 2). Case definition was based on the primary diagnosis; all cases recorded in record books were included in this study. Cases were assigned to a year based on the patient's date of admission.

Gaps in the dataset increased before 1986. Limited data were available for the late 1970s, and no quantitative data were available for the early- to mid-1970s. Interviews were conducted with public health officials to complement and extend 1970s and 1980s data. These officials were chosen by identifying Ugandans actively involved in senior positions in sleeping sickness prevention and control from 1970 to the present and those who could be contacted. They included veterinary and public health managers at the National Ministry of Health or District Medical or Veterinary Office levels. Interviews were used to verify data for the 1980s and to classify disease magnitude for the 1970s.

Sleeping sickness magnitude was classified into 1 of 5 categories for each subcounty for each year: 1) no cases, 2) preepidemic (1-4 cases per year per subcounty), 3) low epidemic (5-15 cases per year per subcounty), 4) high epidemic (16-100 cases per year per subcounty), and 5) extreme epidemic (>100 cases per year per subcounty). These thresholds were based on anecdotal guidance from preliminary interviews and defined to facilitate

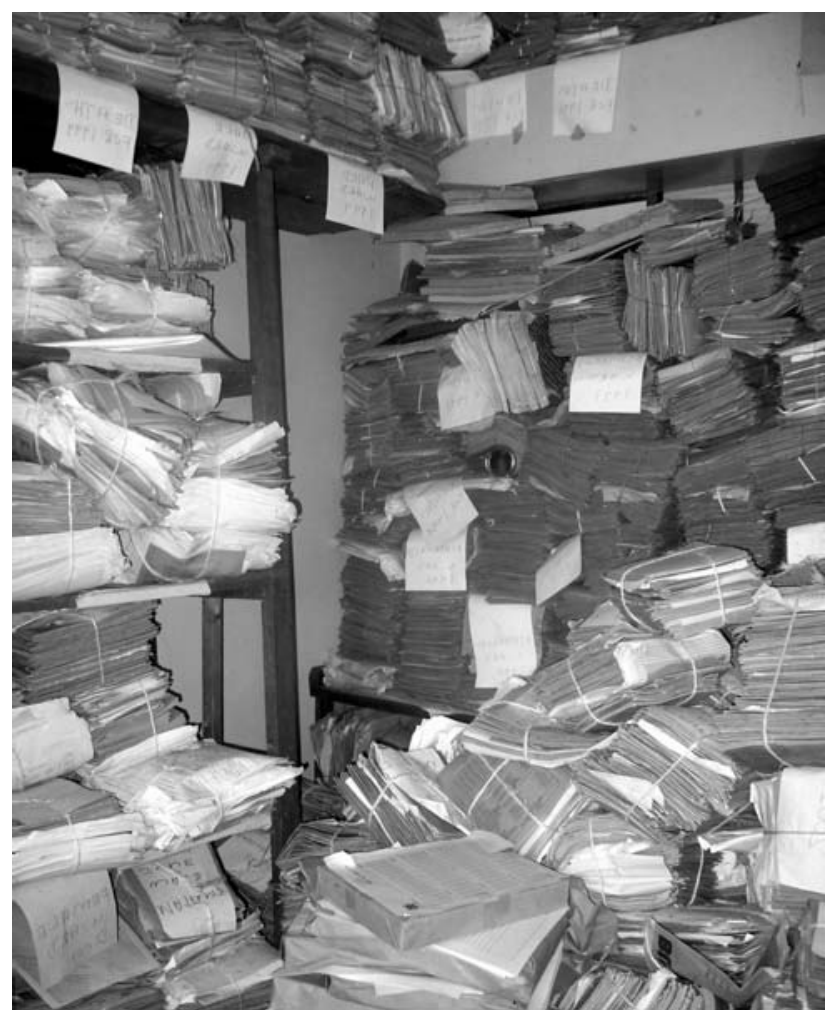

Figure 2. Records room at Bugiri Hospital sleeping sickness treatment center, Uganda. 
standardized definitions of magnitude during subsequent interviews. Interviewer information was compared to available sleeping sickness records and the literature. These results were used to develop a classification database of disease magnitude by subcounty and year. Resulting data and maps were presented to informants for discussion and validation at follow-up interviews in 2005.

The boundaries of political regions changed greatly during the 34-year study period. Aggregation of subcounty data reduced the number of subcounties from 254 in 2004 to 225 for the current study period. Temporal resolution of data is consistent, and aggregation of 29 subcounties is assumed to have little effect on overall analyses.

\section{Data Analysis}

Case counts from 225 subcounties in southeastern Uganda for 34 years (1970-2003) were aggregated into 5 temporal periods for descriptive and geographic cluster analysis on the basis of epidemic progression and data availability: 1970-1975, preepidemic; 1976-1979, ерidemic increase; 1980-1888, epidemic peak; 1989-1997, epidemic decrease; and 1998-2003, epidemic tail. Mean case counts per subcounty per year were calculated for periods in which case counts were available (1980-1988, 1989-1997, and 1998-2003). For earlier periods (1970-1975 and 1976-1979), only ordinal data were available. Therefore, data midpoints were calculated by using the mean of the maximum and minimum ordinal values rounded to the nearest whole number in the direction of the mode. These data were used to develop maps averaging the annual incidences of sleeping sickness for each subcounty during the interval period. Averages of annual incidence for intervals after 1980 were reclassified as sporadic $(<5$ cases/year), low epidemic (5-15 cases/year), or high epidemic ( $>15$ cases/year) to match ordinal data categories for 1970s data.

To identify clusters of sleeping sickness in southeastern Uganda from 1970 to 2003, the space-time scan statistic (14) was used (SaTScan version 5.1 software for spatial and space-time scan statistics available from http://www.satscan.org/ [Kulldorff, Boston, MA, USA and Information Management Services Inc., Silver Springs, MD, USA]). The incidence proportions of the 225 subcounties were assumed to follow a Poisson distribution according to the underlying population size. Cluster analysis results include space-time clusters with no geographic overlap of clusters allowed and a maximum allowable cluster size of $50 \%$ of the population. Space-only and time-only clusters were excluded. Primary and secondary clusters at a significance level of $\alpha=5 \%$ are reported.

Sleeping sickness data were used in the form of case counts per year per subcounty for post-1980 records. For 1970s data, recorded values represent ordinal data (i.e., low, medium, high) rather than case counts. These were transformed to case counts by applying the ordinal minimum value to each record. Population data are based on the 1980, 1991, and 2002 population censuses for Uganda (11). The first 3 analysis periods (1970-1988) used 1980 census records for population counts. Analyses for the periods 1989-1997 and 1998-2003 are based on 1991 and 2002 census records, respectively.

A vector velocity map (15) of sleeping sickness spread was developed by using trend surface analysis (TSA) $(16,17)$. TSA is a global smoothing method using polynomials in geographic coordinates, as defined by the central point of each subcounty polygon. In this case, a trend surface of the year of the first reported sleeping sickness case for each subcounty was used to explore and identify diffusion patterns and corridors of spread over time.

The year of the first recorded case was identified for subcounties in the database. Eighty-nine of 225 subcounties with no recorded cases in the 1970-2003 study period were excluded. The $\mathrm{x}$ - and $\mathrm{y}$-coordinates of subcounty centroids were calculated from a UTM projection shapefile of southeastern Uganda using ArcMAP (ArcGIS 9, Environmental Systems Research Institute, Redlands, CA, USA). Least square regression using linear, quadratic, cubic, and higher-order polynomials of the $\mathrm{x}$ - and $\mathrm{y}$-coordinates to predict year of first reported case was conducted in $\mathrm{R}$ (Foundation for Statistical Computing, Vienna, Austria, available from http://www.R-project.org). Partial differential equations ( $\Delta$ year $/ \Delta \mathrm{X}$ and $\Delta$ year $/ \Delta \mathrm{Y}$ ) were derived from the fitted model, giving a vector of the magnitude (slope) and direction for each location. The square root of the slope equates to the velocity of diffusion.

\section{Results}

\section{Epidemic Curve}

Figure 3 shows the epidemic curve for 1970 to 2003 in southeastern Uganda, as well as a curve of the total number of subcounties infected per year. The latter curve gives an indication of the spatial extent of the disease in the region, while the former indicates the magnitude of the epidemic. The dramatic decrease in incidence in 1982 and 1983 is related to both German Red Cross intervention in 1980 in the Luuka County region (19) (D.B. Mbulamberi, pers. comm.) and reduced surveillance in 1982 and 1983. The number of cases and infected subcounties decreased in the 1990s. In contrast to the decrease in incidence, however, the number of infected subcounties remains well above preepidemic levels.

\section{Incidence Maps and Cluster Detection}

Figures 4-8 show maps of the average annual sleeping sickness incidence ( $T$. b. rhodesiense) per subcounty in 


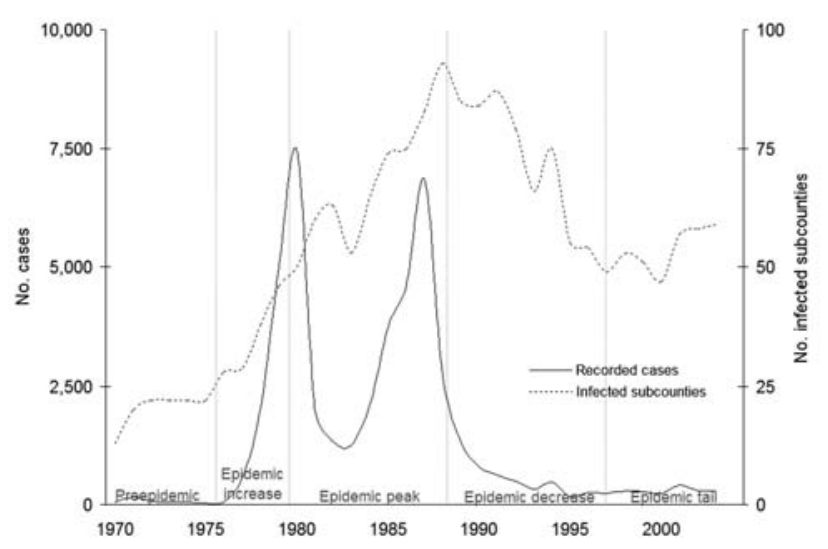

Figure 3. Number of sleeping sickness cases and infected subcounties, southeastern Uganda, 1970-2003. Number of recorded cases refer to totals for southeastern Uganda. Sources: 1970-1971, D.B. Mbulamberi, unpub. data; 1972-1975 (18); and 1976-2001 (Ministry of Health, 2004).

each of the 5 study periods. Legends for the 5 maps are consistent. Each map includes the location of significant $(\alpha=5 \%)$ primary and secondary space-time clusters. Results of cluster detection analyses are discussed below for each interval period and are summarized in the Table. Dominant trends in cluster results were insensitive to maximum cluster size.

\section{0-1975: Preepidemic}

Figure 4 shows the distribution of sleeping sickness that approximates the preepidemic zone of traditional and sporadic infection during the 1960s. Most subcounties are reported as having only a few cases per year. A significant space-time cluster was identified in the area that included the districts of Mayuge, Bugiri, and southern Iganga for 1973-1975 (Figure 4, Table). These cluster results reflect the beginning of incidence increase in these subcounties in the latter half of this period.

\section{6-1979: Epidemic Increase}

Figure 5 shows both an increase in incidence of sleeping sickness along the Iganga/Mayuge/Jinja District borders as well as outward spread of the disease. These processes characterize the onset and increase of the sleeping sickness epidemic in 1976. A 1978-1979 space-time cluster (Figure 5, Table) of smaller size is identified northwest of the cluster for the previous period. The cluster is identified for the later years of the interval, indicating early epidemic onset and propagation, while the smaller radius of the 1978-1979 cluster reflects increased incidence at the epicenter along the Iganga border with Mayuge and Jinja.

\section{0-1988: Epidemic Peak}

Figure 6 shows an extensive increase in both incidence and distribution of sleeping sickness that characterized this peak period of the epidemic. Detection analysis identified a cluster in 1985-1988 (Figure 6, Table) located in the same vicinity as those seen in the 2 previous intervals. The 1985-1988 cluster, in addition to the regions in the 1970s clusters, encompasses areas of Jinja, northern Iganga, and southern Kamuli Districts, indicating continued spatial spread.

\section{9-1997: Epidemic Decrease}

Figure 7 shows the average annual incidence of sleeping sickness for the period 1989-1997. A decrease in overall incidence can be observed in conjunction with continued spatial spread. Cluster detection identified a cluster for 1989-1992 that encompassed the same areas as previous clusters, as well as the Districts of Tororo, Busia, and eastern Mukono (Figure 7, Table). In contrast to the previous periods, a space-time cluster was identified in the first years of the period. This finding reflects a shift in the epidemic from progression to regression. The larger spatial size of the cluster, however, indicates continued spread into new areas (Figure 7). Areas of increased incidence are generally shifted east.

\section{8-2003: Epidemic Tail}

Figure 8 shows the distribution of sleeping sickness incidence for the period 1998-2003. The overall incidence of disease decreased in the southern districts, and the epidemic was characterized by pockets of disease. In addition, the disease was observed for the first time in Soroti District

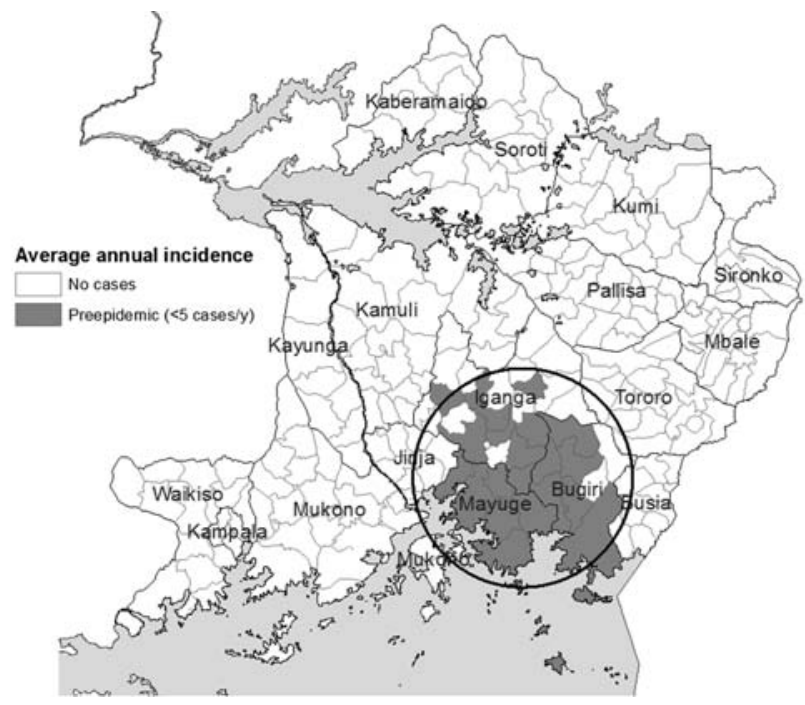

Figure 4. Sleeping sickness incidence, southeastern Uganda, 1970-1975, by subcounty. Circle indicates a significant space-time cluster at the $95 \%$ confidence level, as detected by the space-time scan test. See Table for scan test results. 
Sleeping Sickness, Uganda, 1970-2003

Table. Cluster detection of sleeping sickness, southeastern, Uganda, 1970-2003

\begin{tabular}{|c|c|c|c|c|c|c|c|}
\hline Interval (cluster) & $\begin{array}{c}\text { Districts in most likely } \\
\text { cluster }\end{array}$ & Cluster date & $\begin{array}{c}\text { No. } \\
\text { observed } \\
\text { cases }\end{array}$ & $\begin{array}{l}\text { No. } \\
\text { expected } \\
\text { cases }\end{array}$ & Relative risk ${ }^{\star}$ & $\mathrm{p}$ value & $\begin{array}{c}\text { Cluster } \\
\text { radius }(\mathrm{km})\end{array}$ \\
\hline 1970-1975 & $\begin{array}{l}\text { Mayuge, Bugiri, and } \\
\text { southern Iganga }\end{array}$ & $1973-1975$ & 63 & 8 & 8.3 & 0.0001 & 41 \\
\hline 1976-1979 & $\begin{array}{c}\text { Northwest shift to include } \\
\text { northern Mayuge, Iganga, } \\
\text { Jinja, and southeastern } \\
\text { Kamuli }\end{array}$ & 1978-1979 & 311 & 23 & 13.5 & 0.0001 & 29 \\
\hline 1980-1988 & $\begin{array}{l}\text { Wider extent, including } \\
\text { Mayuge, Bugiri, Iganga, } \\
\text { Jinja, and southern Kamuli }\end{array}$ & 1985-1988 & 13,943 & 1,865 & 7.5 & 0.0001 & 45 \\
\hline 1989-1997 & $\begin{array}{l}\text { As above, plus Tororo, } \\
\text { Busia, eastern Mukono, } \\
\text { southern Kayunga, and } \\
\text { southern Pallisa }\end{array}$ & 1989-1992 & 3,176 & 869 & 3.7 & 0.0001 & 74 \\
\hline 1998-2003 (A)† & $\begin{array}{l}\text { Northwestern Iganga } \\
\text { (Luuka county) and } \\
\text { southern Kamuli }\end{array}$ & 1999-2001 & 331 & 26 & 12.6 & 0.0001 & 19 \\
\hline$(B) \dagger$ & Soroti & $2001-2003$ & 263 & 21 & 12.5 & 0.0001 & 22 \\
\hline (C) $\dagger$ & $\begin{array}{l}\text { Tororo (Osukulu } \\
\text { subcounty) }\end{array}$ & $2001-2002$ & 89 & 7 & 12.9 & 0.0001 & 6 \\
\hline (D)† & $\begin{array}{c}\text { Mukono (subcounties of } \\
\text { Buikwe, Buyikwe, Najja, } \\
\text { Ngogwe, and Ssi) }\end{array}$ & 1998 & 50 & 4 & 12.5 & 0.0001 & $0 \ddagger$ \\
\hline
\end{tabular}

in the north of the study area (cluster B, Figure 8). Cluster detection was consistent with this distribution of outbreak pockets and foci. Four small clusters were detected (Figure 8, Table). Cluster A was detected for 1999-2001 in the subcounties along the border of Iganga and Kamuli Districts. Cluster B identified a new outbreak focus in Soroti District in 2001-2003, where cases were first recorded in 1998. This cluster reflects the increase in incidence in Soroti to the end of the study period. Although incidence in Tororo District peaked around 1990, small outbreak resurgence in Bugongi and Osukuru subcounties in 2001 and 2002 resulted in cluster detection in Tororo District (cluster C, Figure 8, Table) (20). A fourth, smaller, cluster was detected in the subcounties of Buikwe, Buyikwe, Najja, Ngogwe, and Ssi in 1998 (cluster D, Figure 8), which experienced a resurgence of incidence since an earlier peak in 1991.

\section{Trend Surface Analysis}

The results from trend surface analysis are summarized in a velocity vector map (Figure 9). The velocity and direction of diffusion for each coordinate location were mapped to show the movement and instantaneous rate of $T$. $b$. rhodesiense sleeping sickness diffusion in southeastern Uganda over the study period. TSA with high-order polynomials is sensitive to data anomalies at the edge of the study area (15). Less data are available at the study area boundaries; velocity vector size and direction are therefore less reliable and may not be accurate at the edge of the study area. For these reasons, 9 velocity vectors were removed from the vector diffusion map (Figure 9).

The average velocity of sleeping sickness spread over 34 years in southeastern Uganda from 1970 to 2003 was 5 $\mathrm{km} /$ year. Velocity of movement was highest early in the epidemic (Figure 9), when sleeping sickness spread out of its primary focus in southern Iganga District. The epidemic diffused outward in a relatively constant sphere of diffusion from this epicenter. A corridor of movement can be

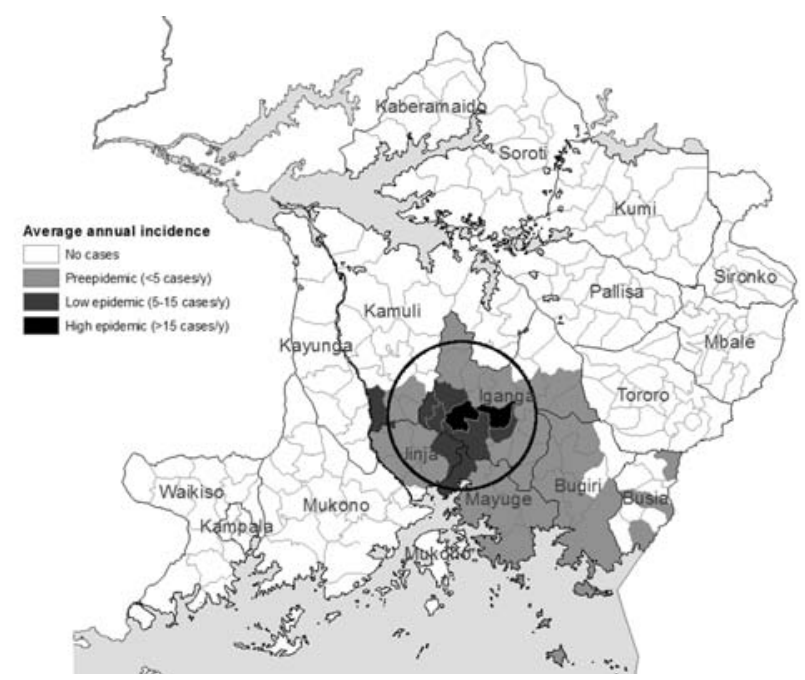

Figure 5. Sleeping sickness incidence, southeastern Uganda, 1976-1979, by subcounty. Circle indicates a significant space-time cluster at the $95 \%$ confidence level, as detected by the space-time scan test. See Table for scan test results. 


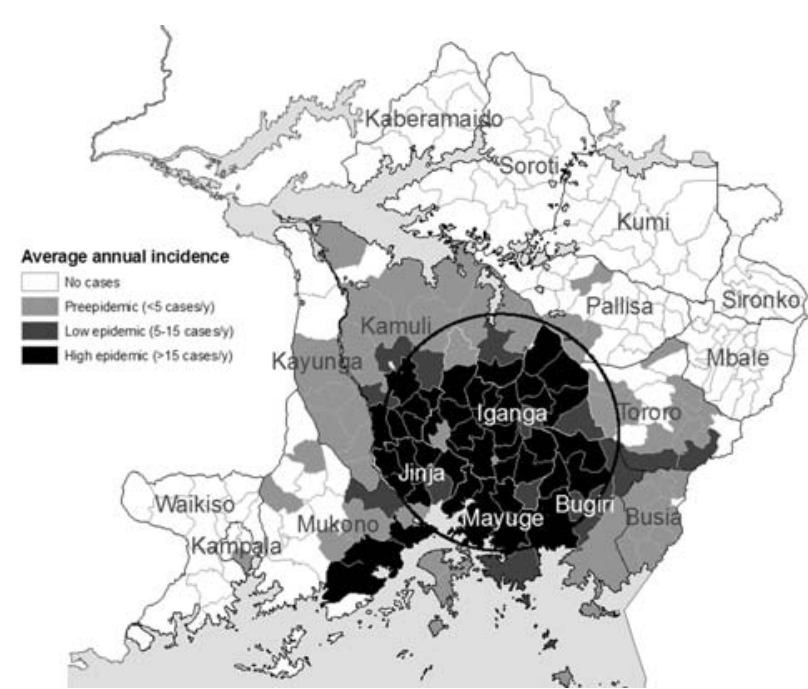

Figure 6. Sleeping sickness incidence, southeastern Uganda, 1980-1988, by subcounty. Circle indicates a significant space-time cluster at the $95 \%$ confidence level, as detected by the space-time scan test. See Table for scan test results.

observed on the eastern fringe of the study area, moving through Busia and Tororo Districts. However, this fringe area should be interpreted with caution because of potential edge effects. The disease moved distinctly north and east into Soroti District. Areas of most rapid spread appear to be the extensions of these 2 corridors north from Soroti and Tororo. These results are consistent with recent detection of cases in the districts of Kumi, Kaberamaido, and Lira $(9,10)$ adjacent to or north of Soroti. Velocity vectors also showed spread west and east. However, Figures 4-8 suggest that much of this horizontal diffusion occurred before the 1990s.

\section{Discussion}

The reliability of data for the 1970s and 1980s is subject to detection and recording bias associated with periods of passive surveillance, missing record books, and recall bias of interviewees. The creation of additional treatment centers over the study period and differential quality of diagnostic and treatment facilities throughout the study area may contribute to spatial bias in the data. Odiit et al. (20-22) discuss the potential for misdiagnosis of cases, selective entry bias around treatment centers, and underdetection of sleeping sickness. Aggregation of cases by subcounty reduces the potential for clustering around individual treatment centers, and unless differential misdiagnosis occurs, it will not critically affect the spatial patterns seen. The data must be interpreted with caution in the context of data reliability and potential biases. Results should be considered exploratory and descriptive; data are not appropriate for direct causal inferences. The results are, however, useful for characterizing broad trends; where historical trends in processes observed are consistent with hypotheses, results can inform current and future research.

T. b. rhodesiense sleeping sickness in southeastern Uganda from 1970 to 2003 followed a pattern of radial spread from its center in southern Iganga District. From 1976 to the 1990s (Figures 4-7), the epidemic trend coincided with civil unrest and political instability in the country. The increase in the epidemic (1976-1979) occurred at a time of increasing political and economic instability, while the peak epidemic period (1980-1988) occurred during the height of political and economic collapse. The decrease in the epidemic (1989-1997) also coincides with increasing stabilization of politics and civil unrest in Uganda. The epidemic trend observed is consistent with our hypothesis (process A) that incidence increases in regions with a history of infection because of changes in human-vector exposure that push the probability of transmission above the required threshold for focal outbreaks. Uganda in the 1970s and 1980s experienced extensive internal displacement of the rural population, illegal human and cattle movements, growth of favorable tsetse habitats on cotton and coffee plantations, and collapse of sleeping sickness prevention and control activities $(8,19,23)$. These events likely contributed to increased human-vector contact and sleeping sickness transmission in the districts around the preepidemic zone of infection.

After the decrease in the epidemic in the 1990s, new outbreaks have been observed in Soroti (1998, Figure 8), Kaberamaido, Kumi, and Lira (2004-2005) Districts $(7,9,10)$. The introduction of the parasite into Soroti District has been linked to cattle restocking from infected

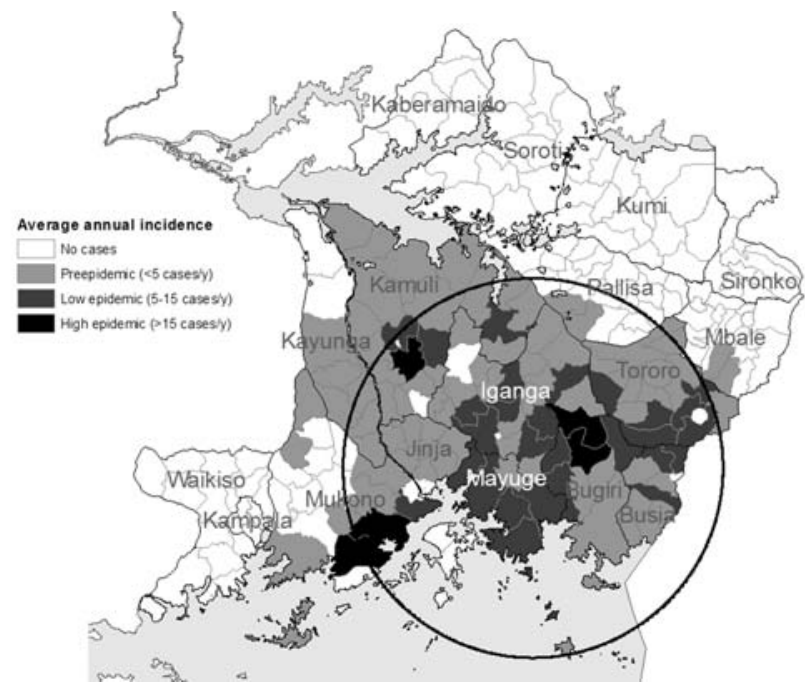

Figure 7. Sleeping sickness incidence in southeastern Uganda, 1989-1997, by subcounty. Circle indicates a significant space-time cluster at the $95 \%$ confidence level, as detected by the space-time scan test. See Table for scan test results. 


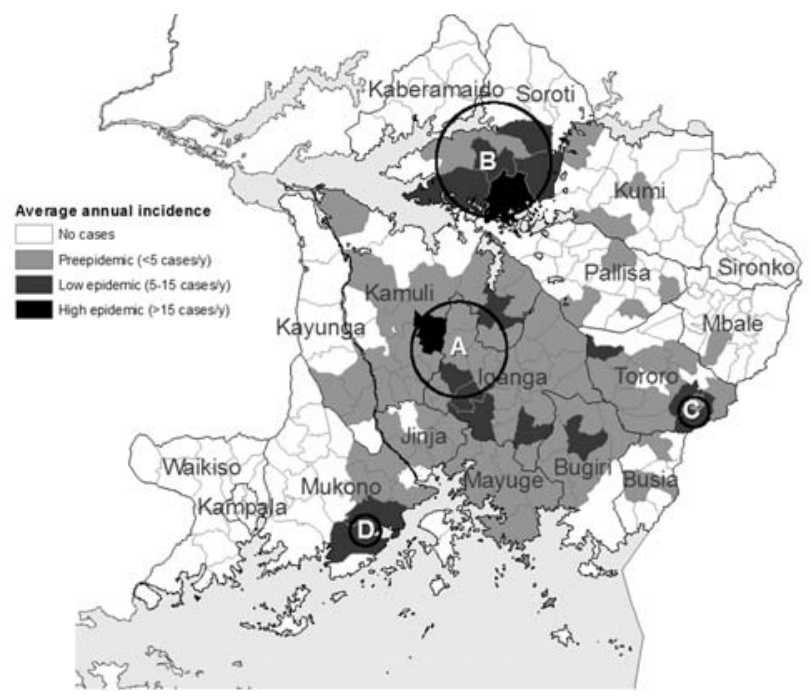

Figure 8. Sleeping sickness incidence in southeastern Uganda, 1998-2003, by subcounty. Circles indicate significant primary (A) and secondary (B, C, and D) space-time clusters at the $95 \%$ confidence level, as detected by the space-time scan test. Letters correspond to cluster results in Table. See Table for scan test results.

southern districts (7). Whether more recent spread into new districts is related to cattle movements is unclear. Postepidemic spread into previously uninfected and peripheral districts since the late 1990s is consistent with our hypothesized second process, which is characterized by parasite spread into new areas through movements of livestock vector. Continuing civil conflict near and within these areas is of particular concern. Once established in

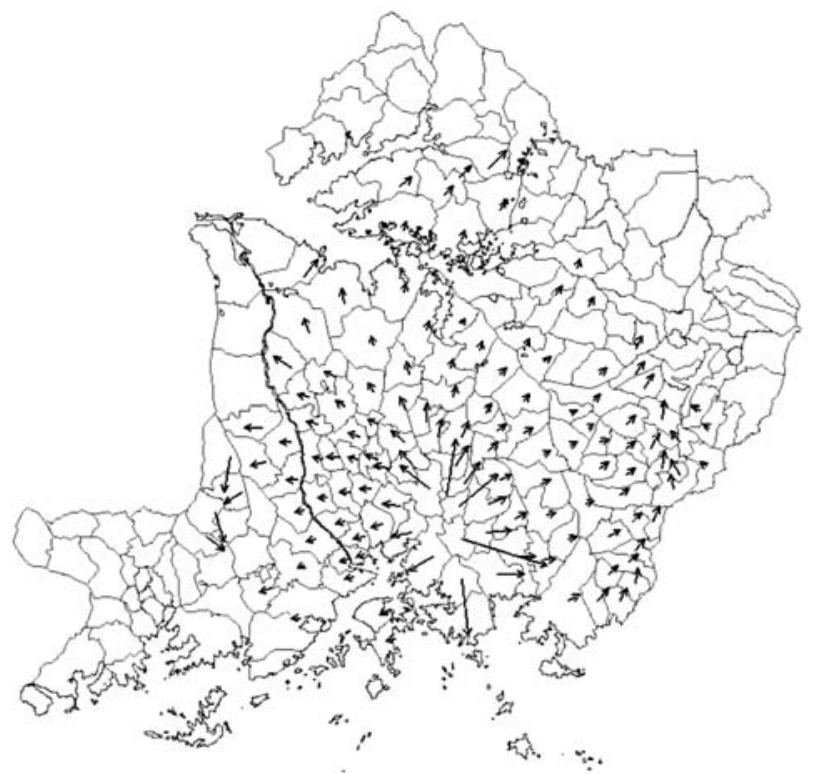

Figure 9. Velocity vectors (arrows) for the spread of sleeping sickness between subcounties in Uganda. Arrow length is proportional to velocity of spread. new regions, processes of transmission may change from introduction of parasites through cattle movements (process B) into proliferation and continued transmission through increased vector-human exposure resulting from effects of civil conflict (process A). The observed historical trends in sleeping sickness, in the context of our hypotheses, support the likelihood of continued spread of $T$. $b$. rhodesiense north from newly infected regions in central Uganda.

Figure 3 suggests that while the number of recorded cases remains low, those cases are coming from an increasing large area. Decreased sleeping sickness surveillance systems in Uganda (D.B. Mbulamberi, pers. comm.) may be missing undetected increases in cases while still detecting infection at the subcounty level. The likelihood of such detection bias is unclear, although a similar difference between recorded cases and recorded subcounties infected preceded the epidemic increase in 1976 (Figure 3). Sleeping sickness is a highly focal disease often characterized by distinct outbreaks in a specific area or village. This outbreak pattern has been smoothed by aggregation of cases to the subcounty level. In spite of the highly focal nature of sleeping sickness, the results suggest a pattern of observable, continuous, and potentially predictable spread of $T$. $b$. rhodesiense sleeping sickness in Uganda when data are smoothed to the subcounty level.

The description and characterization of historical reemergence of sleeping sickness in southeastern Uganda can be used to guide and complement research into the causal processes determining the observed patterns of incidence and spread. These patterns are consistent with our hypotheses of 2 dominant processes of sleeping sickness transmission in southeastern Uganda. First, in regions where disease currently occurs or has recently occurred, localized outbreaks are triggered by changes in vectorhuman exposure or vector numbers, which push the probability of transmission above threshold levels. This process was observed around the traditional infection zone in southeastern Uganda during the 1976-1990 epidemic. Second, in regions where disease has not recently occurred, spread is facilitated by transmission of the parasite thorough livestock. This is currently being observed in the spread of infection to districts in central Uganda that were not infected during the previous epidemic.

Conclusions support further research and intervention related to parasite transmission through cattle movements and potential changes in vector-human exposure in central Ugandan districts. Such analyses are particularly relevant in the context of continued spread of $T$. $b$. rhodesiense sleeping sickness in Uganda, potential merging with $T$. $b$. gambiense subspecies in northwest regions (24), and ongoing civil unrest in north-central regions. 


\section{Acknowledgments}

We thank Lance Waller for providing the R-code used for trend surface analysis; Dawson Mbulamberi, Martin Odiit, and Faustine Maiso for data and research support; the late Thomas Gitau for contribution to early research development; and James Ford for manuscript review.

This work was supported by a grant from the International Development Research Centre, Ottawa, Canada, and by the National Science and Engineering Research Council of Canada.

Ms Lea Berrang-Ford is completing a doctoral degree at the University of Guelph and working as a consultant to the Public Health Agency of Canada. Her research interests include use of spatial analyses and systems approaches to address human and environmental health problems.

\section{References}

1. Jordan AM. Trypanosomiasis control and land use in Africa. Outlook in Agriculture. 1979;10:123-9.

2. Jordan AM. Trypanosomiasis control and African rural development. Harlow (UK): Longman; 1986.

3. Leak SG. Tsetse biology and ecology: their role in the epidemiology and control of trypanosomosis. Wallingford (UK): CABI Publishing in association with the International Livestock Research Institute, Nairobi, Kenya; 1999.

4. Fèvre EM, Coleman PG, Welburn SC, Maudlin I. Reanalyzing the 1900-1920 sleeping sickness epidemic in Uganda. Emerg Infect Dis. 2004;10:567-73.

5. Welburn SC, Fèvre EM, Coleman PG, Odiit M, Maudlin I. Sleeping sickness: a tale of two diseases. Trends Parasitol. 2001;17:19-24.

6. Koerner T, de Raadt P, Maudlin I. The Uganda sleeping sickness epidemic revisited: a case of mistaken identity? Parasitol Today. 1995;11:303-6.

7. Fèvre EM, Coleman PG, Odiit M, Magona JW, Welburn SC, Woolhouse ME. The origins of a new Trypanosoma brucei rhodesiense sleeping sickness outbreak in eastern Uganda. Lancet. 2001;358:625-8.

8. Matovu FS. Rhodesian sleeping sickness in south-eastern Uganda (the present problems). East Afr Med J. 1982;59:390-3.

9. Ministry of Health. Uganda sleeping sickness records. Kampala, Uganda: the Ministry; 2004.
10. Rodriguez A. Trypanosomiasis—Uganda (Kaberamaido). [cited 2005 Jan 27]. Available from http://www.promedmail.org

11. Uganda Bureau of Statistics. Uganda population and housing census, years: 1980, 1991, 2002. Kampala: Government of Uganda.

12. Leggett I. Uganda. Oxford (UK): Fountain Publishers Ltd.; 2001.

13. Jamal V. The agrarian context of the Ugandan crisis. In: Hansen HB, Twaddle M, editors. Changing Uganda: the dilemmas of structural adjustment and revolutionary change. Kampala, Uganda: Fountain Publishers; 2001. p. 78-97.

14. Kulldorff M, Athas W, Feuer E, Miller B, Key C. Evaluating cluster alarms: a space-time scan statistic and brain cancer in Los Alamos. Am J Public Health. 1998;88:1377-80.

15. Waller LA, Gotway CA. Applied spatial statistics for public health data. New York: John Wiley \& Sons; 2004.

16. Moore DA. Spatial diffusion of raccoon rabies in Pennsylvania, USA. Prev Vet Med. 1999;40:19-32.

17. Berke O. Estimation and prediction in the spatial linear model. Water Air Soil Pollution. 1999;110:215-37.

18. Okiria R. The prevalence of human trypanosomiasis in Uganda, 1970 to 1983. East Afr Med J. 1985;62:813-6.

19. Abaru DE. Sleeping sickness in Busoga, Uganda, 1976-1983. Trop Med Parasitol. 1985;36:72-6.

20. Odiit M, Coleman PG, McDermott JJ, Fèvre EM, Welburn SC, Woolhouse ME. Spatial and temporal risk factors for the early detection of Trypanosoma brucei rhodesiense sleeping sickness patients in Tororo and Busia districts, Uganda. Trans R Soc Trop Med Hyg. 2004;98:569-76.

21. Odiit M, Shaw A, Welburn SC, Fèvre EM, Coleman PG, McDermott JJ. Assessing the patterns of health-seeking behaviour and awareness among sleeping-sickness patients in eastern Uganda. Ann Trop Med Parasitol. 2004;98:339-48.

22. Odiit M, Coleman PG, Liu WC, McDermott JJ, Fevre EM, Welburn SC, et al. Quantifying the level of under-detection of Trypanosoma brucei rhodesiense sleeping sickness cases. Trop Med Int Health. 2005;10:840-9.

23. Mbulamberi DB. Possible causes leading to an epidemic outbreak of sleeping sickness: facts and hypotheses. Ann Soc Belg Med Trop. 1989;69(Suppl 1):173-9.

24. Welburn SC, Odiit M. Recent developments in human African trypanosomiasis. Curr Opin Infect Dis. 2002;15:477-84.

Address for correspondence: Lea Berrang-Ford, Department of Population Medicine, University of Guelph, Guelph, Ontario N1G 2W1, Canada; email: berrangl@uoguelph.ca

\section{emerging infectious diseases $\mathrm{O} M \mathrm{l}$ ine}

\section{www.cdc.gov/eid}

To receive tables of contents of new issues send an email to listserve@edc.gov with subscribe eid-toc in the body of your message. 